\title{
O sagrado indígena Tabajara e Potiguara: uma compreensão primeira do saber ambiental em território paraibano
}

\section{Nilma Maria Pôrto de Farias Cordeiro de Medeiros ${ }^{1}$, Cassiano Augusto Oliveira da Silva ${ }^{1}$, Wandson do Nascimento Silva ${ }^{2}$, Sanderline Ribeiro Santos ${ }^{1}$, Carla Jaciara Jaruzo dos Santos ${ }^{1}$, Lusival Antonio Barcellos ${ }^{1}$, Ana Paula Rodrigues Cavalcanti ${ }^{1}$ e Carlos André Macedo Cavalcanti $^{1}$}

\footnotetext{
${ }^{1}$ Universidade Federal da Paraíba. Programa de Pós-Graduação em Ciências das Religiões. Campus I. João Pessoa-PB, Brasil (CEP 58051-900).

${ }^{2}$ Universidade Federal do Ceará. Programa de Pós-Graduação em Geografia. Campus do Pici. Bloco 902. Fortaleza-CE, Brasil (CEP 60440-554). E-mail: wandsongba@hotmail.com.
}

\begin{abstract}
Resumo. 0 presente artigo se configura como um meio para a compreensão imprescindível a respeito de ações e práticas de vida que repercutem diretamente nas questões de qualidade e manutenção da vida e na preservação do meio ambiente e seus recursos. Refletir a respeito de tais questões tem sido uma provocação contínua e um desafio a ser transposto pelas populações e pelos poderes públicos. Assim sendo, nossa pesquisa é um estudo que tem como objetivo refletir sobre a compreensão de uma ética ambiental estabelecida pela convivência do indígena paraibano com a natureza, por meio da ritualística. E a importância desse nosso esforço se estrutura, por ser o rito um fragmento da compreensão primeira da ecologia em território paraibano, por meio dos povos indígenas aqui existentes. Desse modo, consegue-se, a partir de uma abordagem socioantropológica, enxergar o aspecto de preservação ambiental como opus do patrimônio cultural dos povos Tabajara e Potiguara.
\end{abstract}

Palavras-chave: Meio ambiente; Tabajara; Potiguara; Saber ambiental; História.

Abstract. The sacred indigenous Tabajara and Potiguara: $A$ first understanding of environmental knowledge in Paraíba territory. This article is configured as an indispensable means of understanding life actions and practices that directly impact on quality and maintenance issues and the preservation of the environment and its resources. Reflecting on these issues has been a continuous provocation and a challenge to be overcome by
Recebido

23/07/2020

Aceito

02/10/2020

Disponível on line

03/10/2020

Publicado

$31 / 12 / 2020$

Acesso aberto

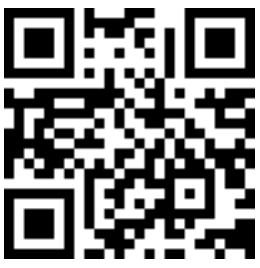

ORCID

(1) 0000-0003-4416-4296 Nilma Maria Pôrto de Farias Cordeiro de Medeiros

ISSN 2359-1412/RBGAS-2020-0111/2020/7/17/3/1087

Rev. Bras. Gest. Amb. Sustent.

http://revista.ecogestaobrasil.net 
populations and public authorities. Therefore, our research is a study that aims to reflect on the understanding of an environmental ethics established by the coexistence of the Paraiba indigenous with nature, through ritualistic. And the importance of our effort is structured, as the rite is a fragment of the first understanding of ecology in Paraíba territory, through the indigenous peoples that exist here. In this way, we were able, from a socio anthropological approach, to see the aspect of environmental preservation as an opus of the cultural heritage of the Tabajara and Potiguara peoples.

Keywords: Environment; Tabajara; Potiguara; Environmental knowledge; History.

\author{
(D) 0000-0002-8461-9104 \\ Cassiano Augusto \\ Oliveira da Silva \\ D 0000-0001-9300-979X \\ Wandson do \\ Nascimento Silva \\ D) 0000-0001-7118-7288 \\ Sanderline Ribeiro \\ Santos \\ (ㄷ) 0000-0003-0805-8664 \\ Carla Jaciara Jaruzo \\ dos Santos \\ (D) 0000-0002-3482-0221 \\ Lusival Antonio \\ Barcellos \\ (D) 0000-0003-4128-5885 \\ Ana Paula Rodrigues \\ Cavalcanti \\ (ㄱ) 0000-0002-7209-0995 \\ Carlos André Macedo \\ Cavalcanti
}

\section{Introdução}

A História do Brasil ressalta a resistência de um povo forte, guerreiro e que luta pelos seus direitos, inclusive ao de um "meio ambiente ecologicamente equilibrado, bem de uso comum do povo e essencial à sadia qualidade de vida, impondo-se ao poder público e à coletividade o dever de defendê-lo e preservá-lo para as presentes e futuras gerações" (Brasil, 1988).

0 fragmento acima é oriundo do caput do art. 225, da Constituição Federal Brasileira de 1988, no entanto, parece que a preservação ambiental já é algo conatural ao âmago dos primeiros povos do Brasil, no caso, os índios Tabajara e Potiguara. A grande mãe, aquela de onde tudo brota, não merece ser violentada, qualquer agressão seria uma ofensa a nós mesmos. Destarte é fácil de compreender que se aquele que agride a natureza não for culpabilizado, os seus descendentes serão.

0 respeito à natureza, à integridade e ao equilíbrio de seus elementos é a lei maior, pautando-se no princípio de que, se a natureza for bem tratada, ela nos regala tudo e, preservá-la é um dever. Sendo assim, a natureza possui energias insondáveis para os mortais e essas energias se manifestam no pajé que se torna seu instrumento. É fato que muitas das atividades indígenas está associada à espiritualidade, cada etapa da vida é marcada por celebrações, através de ritos, danças, cantos e outras, sempre com motivo forte para pedir aos espíritos força. 0 pajé é aquele que detém o conhecimento espiritual e médico, tais conhecimentos abarcam não apenas o quesito fé, mas se associam aos elementos da natureza, não sendo transparente e parecendo ser camuflado pelos recursos da natureza: os animais, a precipitação das chuvas, os astros e tantos outros elementos (Lima, 1998).

As populações indígenas que hoje habitam o Nordeste provêm das culturas autóctones que foram envolvidas em dois processos de territorialização com características bem distintas: o primeiro verificado na metade do século XVII e nas primeiras décadas do século XVIII, associados às missões religiosas; o segundo, ocorrido 
no século XX e articulado com a agência indigenista oficial. Mas antes do final do século XIX, já não se falava mais em povos e culturas indígenas no Nordeste. Destruídos de seus antigos territórios, não são mais reconhecidos como coletividades, mas referidos individualmente como "remanescentes" ou "descendentes" (Oliveira, 2016, p. 207).

A resistência dos povos originários no Nordeste, ocorrida entre 1586 e 1599, culminou diferentes processos de resistência iniciados desde a criação das capitanias hereditárias em 1535. Em 1536, o esforço de ocupar duas capitanias, onde atualmente estão localizados os estados da Paraíba, Rio Grande do Norte, Ceará e Maranhão, foi um fracasso. Os portugueses chegaram em dez navios que conduziam 900 soldados para fundar uma colônia na foz do Rio Grande, onde atualmente localiza-se o Município de Natal, Estado do Rio Grande do Norte. Lá chegando, foram expulsos pelos índios Potiguaras com dezenas de baixas (Grondin, 2018).

E mesmo depois dos portugueses terem conseguido construir o forte do Arraial no Rio Grande do Norte, os Potiguaras não cessaram as reações frente à presença dos brancos. Em 1598, já com sinais de cansaço, resolveram pedir um 'acordo de paz'. Como sempre acontecia, tal 'acordo de paz' representou a morte dos mais fracos, pois a traição dos portugueses chegou logo. E até hoje, o local onde vivem os sobreviventes Potiguaras, com razão, é chamado 'Baía da Traição' (Grondin, 2018).

Afetados pelo processo de territorialização há mais de dois séculos, acabaram tendo como resultados, condições supostamente naturais e adequadas de afirmação de uma cultura diferenciadora. E, portanto, seu patrimônio cultural necessariamente marcado por diferentes fluxos e tradições culturais. "A política indigenista oficial exige demarcar descontinuidades culturais em face das regionais, e assim o processo de territorialização ganha características bem distintas do que ocorreu nas missões religiosas" (Oliveira, 2016, p. 208-209).

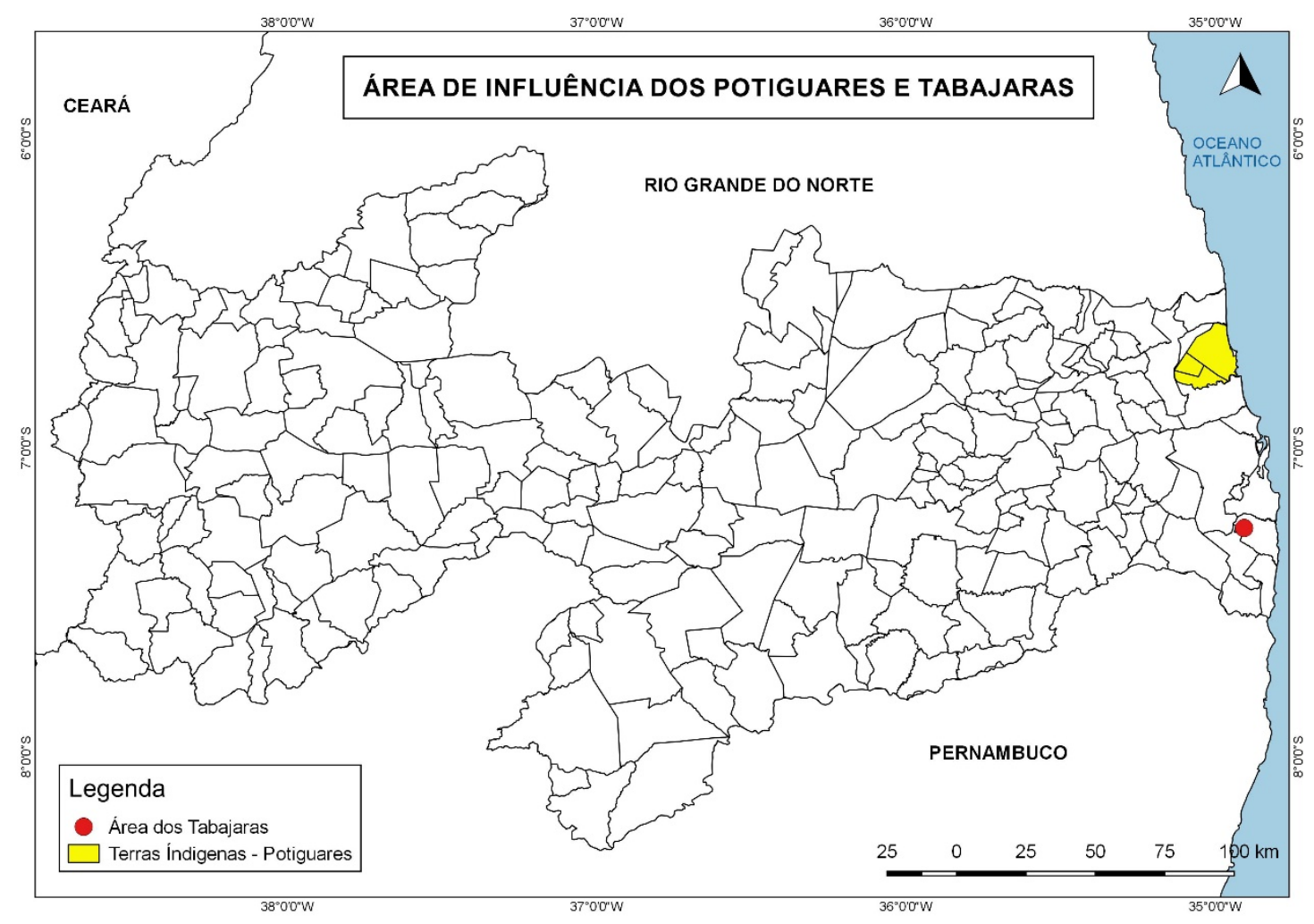

Figura 1. Áreas de influência dos índios Potiguaras e Tabajaras na Paraíba. 
De acordo com Barcellos (2017), no século XVI as nações indígenas no estado da Paraíba totalizavam 18 povos, com mais de 100.000 indígenas. Nos dias atuais, restam apenas duas etnias: uma no litoral Norte, os Potiguara, com aproximadamente 20.000 indígenas, e a outra no litoral Sul, os Tabajaras, com cerca de 1.000 pessoas. 0 passar dos séculos foi áspero para esses povos, pois foram expropriados de seus territórios e, inclusive, os Tabajara foram considerados extintos pela população paraibana (Farias et al., 2014). Assim, como parte da população indígena da Paraíba foi sendo suprimida, os recursos naturais foram seguindo a mesma trajetória histórica. A Figura 1 apresenta graficamente a localização das áreas de influência dos povos Potiguaras e Tabajaras.

A população Potiguara encontra-se distribuída em terras indígenas localizadas entre os rios Camaratuba e Mamanguape, e seu conjunto de aldeias constituem três Terras Indígenas, abrangendo um total de 33.757 ha. A Terra Indígena Potiguara com uma população superior a 8.100 habitantes, a Terra Indígena Jacaré de São Domingos, com uma população superior a 440 habitantes e a Terra Indígena Monte Mór com uma população superior a 4.440 habitantes. 0 referido território situa-se sobre as áreas dos Municípios de Baía da Traição, Rio Tinto e Marcação (Cardoso; Guimarães, 2012). No entanto, os povos Tabajaras apresentam influência no litoral sul da Paraíba, contudo suas terras ainda passam por processo jurídico de identificação e incidem em áreas dos Municípios de Alhandra, Conde e Pitimbu (Terras Indígenas, 2015).

Diante das investidas contra os povos indígenas, em particular povos estes habitantes do território paraibano e, em consequência, também, das investidas contra o meio ambiente e os recursos naturais do estado, este artigo tem como objetivo convidar o leitora refletir sobre a compreensão de uma ética ambiental estabelecida pela convivência do indígena paraibano com a natureza, por meio da ritualística. E sua importância se dá por ser o rito um fragmento da compreensão primeira da ecologia em território paraibano, por meio dos povos indígenas aqui existentes.

Para realização deste artigo científico, foi utilizado como trajeto metodológico a pesquisa bibliográfica. Tipo de pesquisa que ambiciona resolver um problema, ou seja, a hipótese elaborada pelo pesquisador através da reflexão das inúmeras contribuições cientificas já existentes sobre determinado tema, ou discurso científico que fundamente e sirva de base para compreensão de algum evento ou fenômeno, muitas das vezes compreensível apenas por meio da pesquisa bibliográfica.

Nesta realidade, o saber ambiental emerge para a esfera da compreensão de um saber imaginado como um processo em construção e, de extrema complexidade, pois engloba aspectos institucionais, quando do âmbito acadêmico, não contrariando os paradigmas daquilo que é normal na produção de saber, e do nível sociopolítico, através de movimentos sociais e de práticas tradicionais de manejo dos recursos naturais.

O saber ambiental, hoje muito estudado e assumindo função de destaque em nossa pesquisa, especificamente atrelado ao sagrado de um povo, é a forma como os povos indígenas paraibanos possuem para se apresentarem e terem acesso a dimensão da transcendência e da própria subjetividade do homem, fenômeno que a racionalidade cartesiana e as religiões convencionais não seriam capazes de serem sutis a ponto de alcançá-las.

\section{0 indígena paraibano e uma comunicação com o sagrado}

O Povo Potiguara está localizado no litoral Norte do Estado da Paraíba. São 33 aldeias, onde cada uma possui um(a) líder, denominado cacique, que é responsável pela representação política da comunidade e comunicação com a Fundação Nacional do Índio (FUNAI). Há a figura do cacique geral da etnia, considerado como o chefe ou o líder político, que tem influência e autoridade local. Também, há alguns indígenas denominados pajés - que são encarregados pelo apoio espiritual e o cuidado das 
enfermidades por meio das plantas medicinais, bem como efetuar curas através do controle dos espíritos que provocam as doenças e, até mesmo, a morte. Cardoso e Guimarães (2012) destacam que os Potiguara fazem parte dos povos da família linguística Tupi. Na atualidade, falam o português, uma vez que possuem uma longa história de contato com os não-indígenas e de imposição cultural por parte destes.

Sobre os povos Tabajaras em meados do século XIX, ocorreu a expulsão dos indígenas de seu habitat natural, dos seus locais sagrados, do contato com o meio ambiente, ou seja, se afastaram da denominada Mãe Natureza, o celeiro natural desses povos, onde cotidianamente buscavam os recursos para manutenção de sua vida e de sua cultura. Por mais de cem anos ficaram silenciados e tidos com extintos para a sociedade nordestina e nacional. Em 2006, os povos Tabajaras voltaram a ter a visibilidade e a ser reconhecido pelos órgãos governamentais e por toda a sociedade, tendo como agente orgânico desse processo o jovem Tabajara Ednaldo dos Santos Silva, hoje cacique geral. (Farias et al., 2014).

Evidentemente, que a experiência de vida dos indígenas atuais é bem diferente dos seus ancestrais. Muitos habitam nas periferias das grandes cidades, outros nas reservas já delimitadas pelo governo federal, mais existem centenas deles que esperam que a FUNAI inicie todas as etapas para o reconhecimento, a delimitação e a homologação do seu território. Assim, padecendo dos mais diversos tipos de repressão, supressão e preconceito que foram e que continuam sendo vítimas, os indígenas têm mostrado sua bravura e sabedoria ancestral para conviver na sociedade moderna, buscando reavivar e preservar a sua história, sem perder sua identidade étnica e sua tradição milenar (Farias e Barcellos, 2017; Farias et al., 2014).

Ao se pensar em rituais, muitas vezes, duas ideias nos vêm à mente: algo formal e arcaico, quase que desprovido de conteúdo, feito para celebrar momentos especiais e nada mais; e/ou algo ligado apenas à esfera religiosa. Todavia, essas ideias não nos parecem exatas e um dos propósitos desse texto é pensar sobre os rituais, especificamente os indígenas, e como se apresenta seus espaços representativos em nosso meio. Por conseguinte, para os indígenas, os rituais servem para celebrar momentos especiais, onde se apresentam repletos de significações e, por outro lado, estão ligados à religiosidade indígena. Isto é, os rituais estão carregados da tradição e da ancestralidade indígena, fazendo parte da sua própria cultura, transmitidos geralmente entre as gerações pela oralidade.

Pode ser citado ainda, que a religiosidade indígena está fortemente expressa no Toré, que põe em contato os indígenas praticantes com os seus ancestrais e os seres encantados através do contato íntimo com a mãe natureza. Os pés descalços repousam no solo sagrado, a utilização de instrumentos musicais, como tambor, zabumba e o maracá, assemelham-se e se igualam ao som da natureza. A melodia dos cantos, o ruído dos instrumentos citados, guiados por uma autoridade indígena local, geralmente na pessoa do pajé, desenvolvem o Toré. 0 momento é único, o acontecimento é de singular interação com os espíritos dos ancestrais, onde celebram a vida e com eles se comunicam, resolvendo questões do cotidiano indígena, tanto na esfera pessoal, individual, quanto na coletiva.

O ritual do Toré, permite exibir todos os atores presentes na situação interétnica (regionais, indigenistas e dos próprios índios) e os sinais diacríticos de uma indianidade (Oliveira, 2016). Este ritual se constitui como o principal patrimônio dos povos indígenas do Nordeste (Nascimento; Barcellos, 2012). Quanto à pajelança, Laraia (2005) explica que pajé vem do termo pai'é em tupi-guarani, sendo equivalente ao termo xamã, que é utilizado mundialmente e originário de um povo siberiano, os tungus. Eliade (1972), destaca que, desde o princípio do século XX, os etnólogos adotaram o costume de empregar indistintamente os termos xamã, homem-médico, feiticeiro ou mago, para 
designar determinados indivíduos dotados de prestígio mágico-religioso e reconhecidos em todas as sociedades primitivas.

Embora seja de uso corrente, o reconhecimento de um domínio específico da atividade do pajé - perturbações que só ele pode tratar -a sua esfera de ação não se limita a este domínio, mas estende-se sobre uma área muito ampla e nem sempre incompatível com a esfera de ação dos médicos (Pacheco, 2004). Aqui, é possível perceber uma interseção com o processo saúde-doença, onde o pajé tem autoridade e conhecimento para curar. Em contrapartida, pode ser associado o conceito que Csordas (2008) apresenta ao referir o processo de cura como algo mais amplo, que passa pela transformação de uma pessoa, uma vez que o corpo pode ser mostrado, também, como base existencial da cultura.

Em acréscimo, Parés (2011) nos fala de uma pajelança em pelo menos três níveis: a)indígena; b)cabocla, derivada do ritual indígena e com elementos do catolicismo popular ibérico e; c) uma terceira pajelança, mais difundida no estado do Maranhão, especificamente em São Luís, que teria sido formada a partir da apropriação da pajelança cabocla pelos negros. Esse processo de apropriação teria sido facilitado pela convergência de crenças e rituais, ancestralidade e espiritualidade, como explica o autor.

Nos questionamentos de Parés (2011) e Laraia (2005) sobre a origem dos pajés e como são formados, embora exista uma surpreendente uniformidade em seus procedimentos, há uma diversidade de explicações para o seu surgimento. Em alguns casos, trata-se da hereditariedade, isto é, somente podem ser xamãs/pajés os descendentes de outro. No caso Potiguara, o fator hereditário não é necessário, acreditando que se trata de um dom que deve ser descoberto e desenvolvido através do aprendizado.

Ao meditar sobre os rituais, observa-se um caminho inverso dos mitos. Dessa forma, os rituais dispõem-se a contar o mito, recriá-lo e promover uma espécie de retorno a um tempo de indiferenciação, onde divindades, homens, animais e plantas se comunicavam entre si. Isto é, celebram as diferenças entre os seres que habitam o cosmos e, para tanto, alguns artefatos são postos em movimento, como cachimbo, maracá ou maracá, bebida, comida, dentre outros, tudo isto tendo como cenário sagrado o ambiente que o cerca.

\section{A prática ritual do indígena paraibano como ascese ambiental}

Uma ética é uma ascese que se preocupa com a conduta dos indivíduos responsáveis com as paisagens naturais, recursos, espécies e organismos não humanos. Os seres humanos agem em apreensão direta da filosofia moral como tal, desta forma, a ética no sentido exato, "ambiental" vem incluir em seu escopo, perguntas referentes às peculiaridades do meio-ambiente, buscando responder às problemáticas de como preservá-lo, a fim de garantir o futuro da humanidade (Silva, 2010).

Os rituais indígenas envolvem memória e tradição, estando intimamente relacionados. A memória permite a transmissão do que foi dito ao ouvido ("ao pé do ouvido", popularmente expressando) e, uma vez apropriado e praticado coletivamente, torna-se tradição. Portanto, para as nações indígenas, os rituais são tradicionais, enaltecem a ancestralidade, mostram e revigoram suas forças na luta de suas causas, denotam respeito à natureza e, também, são repassados aos seus descendentes. Todos esses ensinamentos ocorrem por meio das vivências e da oralidade (Barcellos e Farias, 2014).

A pajelança é, também, desenvolvida como ritual indígena e os pajés são os únicos com poderes para realizá-la. Vidille (2006) discorre em seu artigo que o pajé estabelece uma comunicação com "espíritos", dos quais ouve explicações a respeito das doenças em questão, da causa e tratamentos necessários, repassando-as ao doente. Em alguns casos, 
complementa a terapêutica com a infusão de ervas colhidas ou com a defumação do corpo do doente. Descreve, ainda, que as doenças são classificadas em duas categorias etiológicas: "naturais" e "apontadas". As doenças naturais podem necessitar de intervenção da ciência, quando o pajé orienta buscar ajuda em hospital, mas, as apontadas são causadas pela "dominação de espíritos maus" e encomendadas por outras pessoas. Nesse caso, os pajés atuam, com exclusividade, afastando esses "maus espíritos", que são os verdadeiros causadores desse tipo de doença. Ainda, exercem suas atividades na esfera preventiva mediante a utilização de benzeção e defumação de pessoas, objetos, comidas, dentre outros.

No âmbito da pajelança, inclui-se o ritual de limpeza, que pode ser do espaço (como a residência, a mata, dentre outros) e da própria pessoa. Entende-se por limpeza a retirada ou o afastamento de "maus espíritos", "energias" negativas, destrutivas, densas e favorecedoras do desequilíbrio de campo energético, tanto ambiental, quanto pessoal. Para esse tipo de ritual emprega-se a utilização de ervas sagradas frescas para ajudar na retirada da "sujeira" e para fortalecer o que será limpo, prevenindo contra novas contaminações. 0 cachimbo é utilizado para a queima de ervas sagradas secas e produção da fumaça, que defuma e auxilia no contato com os seres encantados. E os cânticos e as maracás que, através dos sons produzidos, estreitam as relações com os espíritos ancestrais e os encantados para que se execute o ritual.

O Toré, principal rito da etnia potiguara, é realizado nas festividades sociais, na alegria, na tristeza e na luta, tendo uma abordagem político-social-religiosa intra e extra aldeias. No Toré, são executados movimentos, cantos e toques musicais, cuja autoria remete aos antepassados desses povos, além dos acréscimos de novos elementos textuais, as cantigas. 0 rememorar das lutas e das divindades é uma presença neste momento sagrado. Esse rito cadencia o cotidiano, os tempos, as estações, os lugares, cada ente que compõe ou que compôs a aldeia. Entre os povos Potiguaras, a cerimônia, por meio de sua ritualística, constrói um campo simbólico que vem permitir a provocação de valores e estabelecimento de relações. Assim sendo, há então a possibilidade desse povo de se fortalecer como tal, reforçar sua história em seu habitat natural, sua práxis, além de criar e recriar seus costumes, paixões, hábitos e valores (Nascimento et al.,2012; Pereira e Wanderley, 2018).

Assim como boa parte dos rituais milenares, o ritual de devoção de tais povos indígenas é evidenciada em seus artefatos e no seu vestuário, ocorre uma apresentação dos elementos visuais que caracterizam o indígena, há trajes únicos para cada membro do grupo, ornamentos e pinturas embelezam os corpos dos participantes, músicas e cânticos são entoados com a ajuda de instrumentos musicais. Tudo é preparado antecipadamente, com muita dedicação e afinco, alguns ornamentos e adornos necessitam de um tempo maior para sua elaboração. A produção de uma saia, vai desde a extração da casca de uma arvore que também é utilizada para a construção das jangadas, comumente encontrada nas beiras dos terrenos alagadiços e úmidos. 0 material extraído é colocado de molho numa cacimba para maturar, variando entre 15 e 30 dias a depender da estação do ano, se em tempos de seca ou inverno. É um preparativo que envolve toda a família, os filhos acompanham os pais em cada etapa, desde a coleta da matéria prima para produzir os artefatos, até sua confecção. A relação entre o indígena e o meio ambiente e seus recursos é transmitido para as crianças, que desde tenra infância vai construindo um caráter devocional pelos elementos sagrados do universo indígena, ou seja, o meio ambiente (Nascimento et al., 2012; Pereira e Wanderley, 2018).

Os rituais indígenas são carregados de uma cosmogonia própria, com seus mitos, ritos e espiritualidade. A força da ancestralidade é a própria força do indígena, não há como descrevê-la fidedignamente, apenas vivenciá-la. As práticas ritualísticas exercitadas, durante um longo período histórico, corresponderam às estratégias de resistir e continuar a viver como grupo étnico diferenciado, os rituais forjam a identidade étnica. Nesse 
sentido, a pajelança e o ritual de limpeza são parte de um complexo étnico que norteiam o cotidiano indígena no que concerne ao processo saúde-doença. A figura do pajé dentro de uma aldeia é de extrema importância cosmogônica, pois é sinônimo de contato com os ancestrais e de curas aos necessitados, tanto das doenças "naturais", quanto das "apontadas".

A natureza, através do meio ambiente, proporciona a paz necessária, refletindo na sensação de bem-estar. 0 uso das ervas presentes no meio natural carrega em si efeitos medicinais, ao recordar o mito da criação do remédio, descrito pelo professor, cientista das religiões, mitólogo, filósofo e romancista romeno, naturalizado americano, Eliade (1972, p. 24):

[...] É preciso contar a origem do remédio, caso contrário não se pode falar nele. No tempo em que apareceram o céu, as estrelas, o sol, a lua e os planetas, e em que apareceu a terra", etc., "naquele tempo nasceu Ts'o-dze-p'er-ddu". Segue-se um mito muito longo, que explica a origem dos medicamentos: ausentando-se durante três dias de casa, Ts'o-dze-p'er-ddu encontra, ao regressar, seus pais mortos. Decide então partir em busca de um medicamento que impeça a morte, e vai ao país do chefe dos Espíritos. Após inúmeras aventuras, ele rouba os medicamentos miraculosos, mas, perseguido pelo Espírito, cai por terra e os medicamentos se dispersam, dando existência às plantas medicinais (Eliade, 1972, p. 24).

A maracá é um idiofone de agitamento muito presente na cultura indígena, possui em seu interior uma vasta quantidade de sementes e, desde a sua confecção, simboliza uma série de sentimentos positivos, onde através de seu balançar, além da emissão de sonoridade, emite também uma carga gigantesca de energia positiva. O Povo Potiguara, geralmente, fabrica este instrumento utilizando coco, cabaça ou coité e o cabo é oriundo do galho de uma árvore resistente, ambos - cabeça e cabo - ao serem interligados representam a união entre o ser humano e as forças do universo. Cada semente nele contida passa por um processo de ressignificação, o artesão associa às sementes a alguns sentimentos, que durante o agitar do instrumento são expandidos pelo universo. E também, serve para o chamamento dos ancestrais e encantados que auxiliam e trazem o comunicado do mundo espiritual aos seus usuários (Vieira, 2019).

O cachimbo apresenta em seu formato o cabo e o fornilho que são conectados e representam a união do sagrado feminino com o masculino. São receptores das ervas secas que, unidas aos quatro elementos: fogo, terra, água e ar, dão origem a uma fumaça de odor agradável, que tem por função trazer inúmeros benefícios a quem é alcançado por ela. Durante a defumação, dependendo das ervas utilizadas, essa fumaça tem a capacidade de purificar o ambiente e auxiliar pessoas presentes ou distantes de quem esteja cachimbando. Seguindo a orientação dos encantados, dos caboclos das matas e da Cabocla Jurema (entidades/seres espirituais que auxiliam os trabalhos realizados pelos pajés), o cachimbo e a defumação devem ser utilizados, apenas, para fazer o bem, jamais deverá ser usado com finalidade maléfica (Vieira, 2019).

As ervas frescas são colhidas em horários que respeitam o descanso e o despertar das plantas medicinais. Elas contribuem na exalação de um odor agradável proporcionando tranquilidade, relaxamento, leveza, alívio de dores e problemas respiratórios, além de fornecerem uma renovação energética, sendo colocadas em cima da pessoa ou utilizadas em forma de banho. As ervas também são usadas na limpeza de ambientes (casas, lojas), na produção de pomadas, lambedores, garrafadas, chás e extratos alcoólicos, entre outros produtos fitoterápicos que os pajés produzem para as pessoas que chegam necessitadas de auxílio físico ou espiritual (Vieira, 2019).

No âmbito das Ciências da Saúde, tem-se a Fitoterapia, que se destina ao estudo das plantas medicinais. Várias plantas possuem fito constituintes que detêm ação efetiva 
contra doenças "naturais", comprovadas cientificamente. O Ministério da Saúde (MS) tem apoiado projetos da cadeia produtiva de plantas medicinais e fitoterápicos, por meio de editais. Um exemplo é o Projeto Florir, em Toledo, no Estado do Paraná, que funciona desde 2012 e faz uso de diversas plantas, por exemplo, a passiflora que é utilizada no tratamento da ansiedade em adultos e crianças maiores de 12 anos (MS, 2016). Essa utilização das plantas/ervas é um denominador comum entre os povos, pois é evidente os seus benefícios, o que nos permite apontar uma interseção de práticas que se assemelham, inclusive afinando o objetivo de cura e, dessa maneira vislumbra-se o quanto é possível aprender com os indígenas.

Pintar o corpo é uma marca para os povos indígenas, símbolos próprios representam cada grupo étnico e, aos participantes dos rituais conferem atributos e também podem ser entendidas como elementos identitários, há aí um reforço a condição de ser índio. Os indígenas se revestem da pintura no ritual do Toré e também nos momentos de reivindicações políticas e eventos. Do urucum se extrai a coloração vermelha e do jenipapo a cor preta, estes são frutos achados em fartura na região. 0 modo de se preparar a tinta pode variar, podendo ser cozinhada ou misturada com álcool ou mel, estes ajudam no impregnar do pigmento, tendo como exemplo o caso do jenipapo, a pintura fica em média de 15 dias na pele, sem perder a coloração (Pereira e Wanderley, 2018; Barcellos e Farias, 2014).

Cada nação indígena tem seu jeito se ser, cada um com sua musicalidade, dança, coreografia e várias formas de estabelecer contato com os ancestrais. Por essa perspectiva, destacam-se o canto, a musicalidade, como meio de conexão. Segundo Monteiro (2006), os xamãs sabiam que a palavra cantada tem um sentido de presentificação, tornando possível romper os limites de suas possibilidades físicas de movimento e visão, entrando assim, em contato com novos fatos e mundos, que se tornavam audíveis, visíveis e presentes, através do poder do canto. Os rituais indígenas são uma composição de homem (indígena e nãoindígena, como a paciente citada), música (cânticos e sons de instrumentos musicais), fumaça (cachimbo e a queima de ervas sagradas), fé (crença em seus ritos e mitos) e, extraordinariamente, esperança (contida na espiritualidade).

Eliade (1972, p. 24) faz pontuações sobre os cantos rituais indígenas, extrai-se o trecho a seguir:

A maioria desses cantos rituais de fins terapêuticos começa por evocar a cosmogonia. Eis um exemplo: 'No princípio, no tempo em que os céus, o sol, a lua, as estrelas, os planetas e a terra ainda não haviam aparecido, quando ainda nada havia aparecido, etc'. E conta-se a criação do mundo, o nascimento dos demônios e o aparecimento das enfermidades, e, finalmente, a epifania do Xamã primordial Dto-mba, que forneceu os medicamentos necessários. Um outro começa pela evocação do tempo mítico: 'No começo, quando tudo era indistinto, etc.', para contar o nascimento dos Nâgas e dos Garudas. A seguir é contada a origem da doença..., os meios pelos quais é propagada de uma geração a outra e, finalmente, a luta entre os demônios e o xamã: 'O espírito, arremessando a flecha, dá doença aos dentes e à boca, o Dto-mba arranca a flecha, etc.; o demônio dá doença ao corpo, arremessando a flecha no corpo, o Dto-mba a arranca, etc.

Por fim, o cenário onde tudo isto ocorre é a natureza, a total dependência da criatura com o mundo sobrenatural se dá de forma primeira através daquela com o mundo natural. Há no estilo das populações indígena um saber ecológico e, para Boff (1993) a ecologia pode ser entendida de forma sintética por meio de três vieses distintos, mas intimamente relacionados. 0 primeiro seria a ecologia ambiental, que trata da relação entre ser humano e meio ambiente. 0 segundo, a ecologia social, que trata da relação entre os seres humanos dentro das relações com o ambiente (a questão do acesso aos recursos naturais, a desigualdade socioeconômica). 0 terceiro, a ecologia mental, que trata da 
natureza tal como representada no interior da mente sob a forma de energias psíquicas, símbolos, arquétipos e padrões de comportamento.

De acordo com Boff (1993), a interação do indígena com a terra é algo muito interessante e que motiva um olhar para si e para suas ações, naquele que com a qual se depara. 0 ser humano, nas várias culturas e fases históricas, revelou essa percepção segura. Temos íntima relação com a terra, somos gerados pela terra, portanto também, somos terra. Não se trata de algo diferente da natureza humana, somos a própria terra que na sua evolução chegou ao estágio de sentimento, de compreensão, de vontade, de responsabilidade e de veneração. Somente conhecendo a história do universo e da terra, conheceremos a nós mesmos e a nossa ancestralidade.

Refletir sobre como os povos indígenas vivem e interagem com a natureza vem instigar em nós uma necessidade de uma consciência ecológica. Grosso modo, vem nos convidar a refletir sobre nossa capacidade de nos compreender como parte de um meio com o qual existe relações em interdependência, com o qual se estabelece trocas de gratuidades, favores e serviços, submetendo tudo isso a uma hierarquia de valores que tudo norteia e a tudo dá significado em vista da mútua realização e perfeição.

\section{O protagonismo indígena da Paraíba e a preservação do meio ambiente e seus recursos}

0 preocupar-se com as questões do meio ambiente também partem do úbere da ética indígena, em favor do índio e de todos os povos indígenas. Estes sempre estão em interação com o mundo natural, o meio ambiente e os recursos naturais não são uma realidade intocada, a manutenção da vida para estes povos advêm da relação com o meio ambiente, deste se tira o alimento necessário e se protege contra as enfermidades, tudo isto dentro de um cenário de espiritualidade, de um arrolamento entre o povo indígena, o meio ambiente, os recursos naturais e o sagrado.

A pesca e da coleta de frutos estacionais são os recursos de sobrevivência do povo Tabajara. Os rios e o mar permitem a pesca de peixes diversos e crustáceos, particularmente camarões. A cultura de subsistência com o plantio de cereais, algumas raízes, legumes, verduras e frutas é uma realidade. Contudo, a venda de frutas à turistas a margem da rodovia PB-008, em período de safra, também é um meio para se conseguir alguns recursos financeiros. A criação de animais também figura entre esses povos, sãos patos, galinhas, porcos e bovinos. Já os povos Potiguaras tem a terra como "mãe" e tanto essa como as matas são tidas por sagradas, dali retiram troncos, galhos, raízes, cascas, folhas, flores e tantos outros insumos para a produção dos unguentos e remédios caseiros muito comuns na prática curativa indígena e, alguns que são compostos químicos base para produção de medicamentos da medicina alopática. Os sinais sacramentais são vistos e recolhidos nas matas. 0 meio ambiente e seus seres animados e inanimados tem algo que o atrela ao sagrado. Não só os reinos animal e vegetal estão integrados nesse universo indígena, há uma mitologia própria que adorna e dão sentido à vida dos povos indígenas da Paraíba (Barcellos, 2012).

$\mathrm{Na}$ atualidade é sabido que a temática ambiental exige o compromisso e a responsabilidade de todos, a gravidade dos problemas ecológicos determinam uma efetiva transformação de mentalidade que induza a adoção de novos estilos de vida, nos quais a busca do verdadeiro, do belo e do bom, e a comunhão com os outros homens, em ordem ao crescimento comum, sejam os elementos que determinam as opções do consumo, da poupança e do investimento. Esses estilos de vida devem ser inspirados na sobriedade, na temperança, na autodisciplina, no plano pessoal e social. Para que as muitas sociedades atuais assemelhem-se aos povos indígenas é necessário sair da lógica do mero consumo e promover formas de produção que respeitem a ordem daquilo que algumas civilizações e 
religiões compreendem como a criação, buscando satisfazer apenas aquilo que se compreende como necessidades primárias de todos.

Uma semelhante atitude, favorecida por uma renovada consciência da interdependência que une todos os habitantes da terra, concorre para eliminar diversas causas de desastres ecológicos e garante uma tempestiva capacidade de resposta quando tais desastres atingem povos e territórios (Silva et al., 2015, p. 52).

Quando se aborda os temas da Ecologia, do Eco Desenvolvimento e do Desenvolvimento Sustentável é imprescindível aprofundar-se no saberes tradicionais como aqueles advindo da cultura dos povos indígenas, uma vez que esses podem permitir uma utilidade mais proveitosa e efetiva dos recursos naturais e do meio ambiente, satisfazendo objetivos distintos, mas que sejam capazes de dialogarem entre si, tendo por norteio, a conservação e a continuação cultural dos povos, da diversidade biológica, além da proteção das riquezas ambientais. Desta forma o Desenvolvimento Sustentável apresenta-se como sendo um processo de desenvolvimento capaz de suprir as necessidades atuais sem comprometer a capacidade das futuras gerações de satisfazer suas próprias necessidades (ONU, 1987).

Faz-se necessário compreender que as formas de convívios sociais se constituem de vários povos onde a pluralidade, o hibridismo, a mestiçagem e as subculturas de cosmovisões são determinantes para compreensão do surgimento de muitas nações, principalmente da nação brasileira. Assim, quando se refere a um modo de vida, não está postulando a respeito da determinação de padrões, mas de objetivos comuns para a preservação da espécie humana por meio da preservação do meio ambiente e dos recursos naturais. Por entre os povos e nações, a questão ecológica deve traduzir-se, sobretudo, em uma forte motivação para uma autêntica solidariedade de dimensão universal, o mundo nos reconduz ao mistério de Deus/Deuses, que o criou/criaram e o sustém (Vilhena, 2005).

Quando se estuda como vivem os povos primeiros destas terras ou, quando vai in loco observar essa realidade, conclui-se um modus operandi concreto de uma ascese ambiental tradicional, característica de um povo, com foco na sustentabilidade, onde a dinâmica social é o regente. As cerimônias, os rituais, os ciclos reprodutivos estão amalgamados com os ciclos ecológicos que geram os ciclos produtivos (caça, pesca, coleta, uso da terra entre outros) e tudo isto não se caracteriza apenas como atividades produtivas, nem como necessidades corporais de sobrevivência, mas como obrigações pedagógicas, espirituais e morais. É justamente a sustentabilidade físico-cultural que vem assegurar a sustentabilidade ambiental dos povos indígenas, isto conduzido por um respeito sóbrio ao meio ambiente.

É preciso compreender que os princípios vivenciados pelos povos indígenas se encontram em consonância harmônica com o conceito de sustentabilidade. Boff (2012) entende a sustentabilidade como uma ação que tem como objetivo a preservação das condições energéticas, físicas e químicas que proporcionem a sustentação de todos os seres vivos e, por conseguinte, mantendo a terra viva. Sendo assim, visa-se à continuidade da vida, de modo a atender a necessidades das gerações atuais e das futuras e que o capital natural permaneça mantido e enriquecido na capacidade de se regenerar, reproduzir e coevoluir. Para Lozano (2012), a sustentabilidade condiz com crescimento econômico, no entanto é preciso pautar na justiça social e eficiência no uso dos recursos naturais.

O domínio do meio natural dá-se através da compreensão, há uma linguagem própria desses povos com a natureza, o funcionamento dela é muito bem compreendido por aqueles, a mística traçada pelas forças e pelos mistérios são honradas e respeitadas, uma vez que para que haja sustentabilidade faz-se necessária a capacidade de se respeitar 
a natureza e suas formas. Assim sendo, abordar um pouco dos povos indígenas paraibanos - Potiguaras e Tabajaras - dentro daquilo que esses possuem como estilo de vida e como os ritos sagrados cooperam para uma práxis de preservação do meio ambiente e dos recursos naturais.

\section{Conclusão}

No transcurso da leitura deste artigo foi possível enxergar que o meio ambiente e seus recursos sofreram e, ainda sofrem, com as ações do homem contra o meio ambiente, seus recursos naturais e contra os seres irracionais e racionais. É interessante citar que no ano de 2020 o mundo vem sendo assolado pelo coronavírus, agente etiológico da Síndrome Respiratória Aguda Grave 2 (SARS-CoV-2), vírus causador da Doença do Coronavírus 2019 (COVID-19), e que pouco se sabe a seu respeito, mas que teve uma propagação global em pouquíssimo tempo. "A velocidade e intensidade da contaminação populacional pelo vírus levou a Organização Mundial da Saúde (OMS) a classificar a doença como pandemia em 11 de março de 2020" (Porsse et al., 2020).

Atualmente, mais do que nunca, é preciso começar a repensar a forma como as sociedades estão se erigindo e se transformando numa realidade de puro consumismo e destruição dos recursos da natureza. Estar no auge do seu desenvolvimento não significa detenção imperativa do saber, em específico do saber ambiental. Observa-se neste artigo que a sabedoria dos povos indígenas paraibanos no que tange a esfera do sagrado, através dos seus ritos é detentora de um riquíssimo saber ambiental, pautado no respeito e na obediência àquela que o mantém e os harmoniza como ser humano e como comunidade.

O saber ambiental entre os povos indígenas da Paraíba é envolvente, é gregária, isso desde as atividades mais rudimentares, até aquelas mais complexas, isso na realidade daquele povo. A identidade destes está intimamente ligada ao meio ambiente e seus recursos e, caráter devocional pelos elementos sagrados do universo indígena - o meio ambiente - é uma característica que os reflete no imaginário de qualquer ser humano quando motivado pelo mote racional.

Assim sendo, apesar de nosso esforço intelectual ter tomado por foco uma reflexão sobre a compreensão de uma ética ambiental estabelecida pela convivência do indígena paraibano com a natureza. Faz-se necessário que as sociedades contemporâneas entendam que preservação ambiental e a sustentabilidade constituem-se a partir de uma relação harmônica entre meio ambiente, sociedade e economia. E nossos povos primeiros estão aí como mestre, dentro de sua realidade sócio-antropológica.

\section{Conflito de interesses}

Os autores declaram não haver conflito de interesses.

\section{Referências}

Boff, L. Ecologia, mundialização e espiritualidade. São Paulo: Ática, 1993.

Boff, L. Sustentabilidade: o que é, o que não é. Petrópolis: Vozes, 2012.

Barcellos, L.; Farias, E. Os indígenas da Paraíba. In. Flores, E. C. Diversidade Paraíba: indígenas, religiões afro-brasileiras, quilombolas, ciganos. João Pessoa: Grafset, 2014. p. 11-48.

Brasil. Constituição da República Federativa do Brasil de 1988. Disponível em: <http://www.planalto.gov.br/ccivil_03/constituicao/constituicao.htm>. Acesso em: 16 jul. 2020. 
Cardoso, T. M.; Guimarães, G. C. (Orgs.). Etnomapeamento dos Potiguaras da Paraíba. Brasília: FUNAI/CGMT/CGETNO/CGGAM, 2012. (Série Experiências Indígenas, 2).

Barcellos, L. Práticas educativo-religiosas dos Potiguaras da Paraíba. João Pessoa: Editora da Universidade/UFPB, 2012.

Csordas, T. J. Corpo/Significado/Cura. Porto Alegre: Editora UFRGS, 2008.

Eliade, M. Mito e realidade. São Paulo: Perspectiva, 1972.

Farias, E. S.; Barcellos, L. A. Jovens indígenas Tabajara: âncoras no processo de reinvindicações na busca do bem viver no século XXI. Revista Tecnologia e Sociedade, v. 13, n. 29, p. 116-130, 2017. https://doi.org/10.3895/rts.v13n29.5042

Farias, E. S.; Flores, E. C.; Fonseca, I. S.; Rodrigues, J. M. C.; Barcellos, L. A. Diversidade Paraíba: indígenas, religiões afro-brasileiras, quilombolas, ciganos. João Pessoa: Grafset, 2014.

Grondin, M.; Viezzer, M. 0 maior genocídio da história da humanidade: mais de setenta milhões de vítimas entre os povos originários das Américas - resistência e sobrevivência. Toledo: GFM Gráfica \& Editora, 2018.

Laraia, R. B. As religiões indígenas: o caso tupi-guarani. Revista USP, n. 67, p. 6-13, 2005.

Lima, Z. 0 mundo místico dos Caruanas e a revolta de sua ave. Belém: CEJUP, 1998.

Lozano, R. Towards better embedding sustainability into companies' systems: na analysis of voluntary corporate initiatives. Journal of Cleaner Production, v. 25, p. 14-26, 2012. https://doi.org/10.1016/j.jclepro.2011.11.060

Monteiro, A. V. V. Xamanismo: a arte do êxtase. eBooksBrasil.org, 2006. Disponível em: <http://www.ebooksbrasil.org/adobeebook/xamanismo.pdf>. Acesso em: 13 jun. 2019.

MS - Ministério da Saúde. Fitoterápicos e ervas medicinais podem substituir medicamentos sintéticos no tratamento de algumas doenças. 2016. Disponível em: <http://www.blog.saude.gov.br/index.php/promocao-da-saude/50835-fitoterapicos-eervas-medicinais-podem-substituir-medicamentos-sinteticos-no-tratamento-de-algumasdoencas>. Acesso em: 10 jun. 2020.

Nascimento, J. M. (Org.). Etnoeducação Potiguara: pedagogia da existência e das tradições. João Pessoa: Ideia, 2012.

Oliveira, J. P. 0 nascimento do Brasil e outros ensaios: "pacificação", regime tutelar e formação de alteridades. Rio de Janeiro: Contra Capa, 2016.

ONU - Organização das Nações Unidas. Relatório da Comissão Mundial Sobre o Meio Ambiente e Desenvolvimento. Assembleia Geral, 42/187, 1987. Disponível em: <http://www.un.org/documents/ga/res/42/ares42-187.htm>. Acesso em: 10 jun. 2020.

Pacheco, G. B. F. Brinquedo de cura: um estudo sobre a pajelança maranhense. Rio de Janeiro: Museu Nacional, 2004. (Tese de doutorado).

Parés, L. N. Apropriações e transformações crioulas da pajelança cabocla no Maranhão. In: Carvalho, M. R.; Reesink, E.; Cavignac, J. (Orgs.). Negros no mundo dos índios: imagens, reflexos, alteridades. Natal: EDUFRN, 2011.

Pereira, E. D. F.; Wanderley, I. M. Análise da arte indígena da etnia potiguara e suas colaborações para o design. Anais do 14ํㅡㄹ Colóquio da Moda, Curitiba, PUC-PR, 2018. Disponível em: <http://www.coloquiomoda.com.br/anais>. Acesso em: 06 jul. 2020. 
Porsse, A. A.; Souza, K. B.; Carvalho, T. S.; Vale, V. A. Impactos econômicos do CoVID-19 no Brasil. Curitiba: Universidade Federal do Paraná, 2020. (Nota Técnica NEDUR-UFPR, n. 01-2020). Disponível em: <http://www.nedur.ufpr.br/portal/wpcontent/uploads/2020/04/nota-tecnica-nedur-ufpr-01-2020-impactos-economicos-dacovid-19-no-brasil.pdf>. Acesso em: 06 jul. 2020.

Silva, C. A. O.; Gama, C. L. M.; Nascimento, K. T. L. Meio ambiente e fé católica: um discurso em busca de uma práxis pastoral. Revista Último Andar, n. 26, 2015. Disponível em: $<$ https://revistas.pucsp.br/ultimoandar/article/view/26124/18753>. Acesso em: 14 jul. 2020.

Silva, E. G. Religiosidade e meio ambiente: das críticas dos ambientalistas à construção de uma ecoteologia. Revista Eletrônica Espaço Teológico, v. 4, n. 6, p. 132-140, 2010.

Terras Indígenas. 2015. Disponível em: <https://terrasindigenas.org.br/pt-br/terrasindigenas/5422>. Acesso em: 17 jul. 2020.

Vidille, W. Xamãs e os espíritos ancestrais. Psychê, v. 10, n. 19, p. 47-64, 2006.

Vieira, J. G. Catimbó e toré: práticas rituais e xamanismo do povo potiguara da Paraíba. Vivência Revista de Antropologia, n. 54, p. 41-64, 2019.

Vilhena, M. A. Ritos: expressões e propriedades - temas do ensino religioso. São Paulo: Paulinas, 2005.

Informação da Licença: Este é um artigo Open Access distribuído sob os termos da Licença Creative Commons Attribution, que permite uso irrestrito, distribuição e reprodução em qualquer meio, desde que a obra original seja devidamente citada. 